ENCYCLOPEDDIE Encyclopédie berbère

BERBERE

1 | 1984

1 | Abadir - Acridophagie

\title{
Abū Hammū Musa
}

(Voir Abd-el-Walide)

C. El Briga

\section{OpenEdition}

\section{Journals}

Édition électronique

URL : http://journals.openedition.org/encyclopedieberbere/795

DOI : 10.4000/encyclopedieberbere.795

ISSN : 2262-7197

\section{Éditeur}

Peeters Publishers

\section{Édition imprimée}

Date de publication : 1 novembre 1984

Pagination : 88-89

ISBN : 2-85744-201-7

ISSN : $1015-7344$

\section{Référence électronique}

C. El Briga, «Abū Hammū Musa », Encyclopédie berbère [En ligne], 1 | 1984, document A24, mis en ligne le 01 décembre 2012, consulté le 05 octobre 2020. URL : http://journals.openedition.org/

encyclopedieberbere/795; DOI : https://doi.org/10.4000/encyclopedieberbere.795

Ce document a été généré automatiquement le 5 octobre 2020.

(c) Tous droits réservés 


\title{
Abū Hammū Musa
}

\author{
(Voir Abd-el-Walide)
}

\section{El Briga}

1 Nom porté par deux souverains de la dynastie des Abd el-Wadides de Tlemcen.

Abū Hammū Musa I ${ }^{\text {er }}$ régna de 707/1308 à 718/1318 successeur de Abū Zaiyān, il est le quatrième roi abd-el-wadide. Il réussit à contenir les Mérinides et après avoir assis son autorité sur les tribus remuantes du Chélif et du Titteri il envoie vers l'est des expéditions contre Bougie et Constantine. Sur le plan intérieur il restaure la ville de Tlemcen qui avait considérablement souffert des huit ans de siège mérinide (1299-1307). Il fait construire de nouveaux remparts. Cependant il semble avoir rencontré une opposition violente auprès de ses sujets, son fils Abū Tashfin 1er ayant gagné la confiance d'une partie de l'armée le fait assassiner et s'empare du pouvoir en $718 / 1318$.

2 Abū Hammū Musa II - Restaurateur du royaume abd-el-wadide en 774/ 1372. Né et élevé en Espagne, tandis que régnaient à Tlemcen ses deux oncles Abū Said et $A b \bar{u}$ Thābit, Abū Hammū devint un fin lettré. Rentré à Tlemcen, il subit le sort de sa famille lors de la bataille de la plaine d'Angād ; avec l'un de ses oncles survivant, Abū Thābit, il s'enfuit et trouva refuge, après la mise à mort de son oncle, à Tunis où il fut bien accueilli par les Hafsides. Ces derniers trouvèrent en Abū Hammū un auxiliaire utile dans la longue lutte d'influence qui les opposait aux Mérinides. La mort du sultan mérinide Abū 'Inan favorise le retour d'Abū Hammū ; en 760/1359 il est proclamé roi. Mais ce n'est qu'un moment de répit, les Mérinides occupent à deux reprises Tlemcen et de nouveau en 772/1370 : cette fois la cause d'Abū Hammū semble définitivement anéantie : le chef abd-el-wadide se réfugie au Mzab et les armées de Fès occupent tout le royaume. Cette conquête demeure cependant précaire et la mort du sultan Abū Faris 'Abd el-Azziz en 774/1372, suivie de l'évacuation de l'armée mérinide, permet aux Tlemcéniens de rappeler leur souverain. Mais la fin de son règne demeure troublée, cette fois-ci par des querelles intestines suscitées par son fils aîné Abū Tašfin* qui, avec l'aide des Mérinides le vainquit devant Tlemcen. Abū Hammū, qui avait composé un traité de morale à l'usage de ce même fils ("Le chapelet de perles») périt les armes à la main, et sa tête plantée au haut d'une pique fut présentée à Abū Tašfin (1389). 
3 Pendant ce règne si malheureux, Tlemcen connut cependant, sous l'influence de ce prince lettré et artiste, de brillantes fêtes, en particulier lors de la célébration du Mouloud, dont les chroniqueurs ont laissé la description, ainsi que celle de la fameuse horloge du palais d'Abū Hammū.

\section{BIBLIOGRAPHIE}

Voir Abd-el-Wadide.

INDEX

Mots-clés : Algérie, Biographie, Moyen Âge 